Published in final edited form as:

Ophthal Plast Reconstr Surg. 2017 ; 33(2): e43-e44. doi:10.1097/IOP.0000000000000716.

\title{
Giant Chondroid Syringoma of the Lower Eyelid
}

\author{
Lauren E. Hudson, BS ${ }^{1}$, Caroline M. Craven, MD $^{1,2}$, Ted H. Wojno, MD ${ }^{1}$, and Hans E. \\ Grossniklaus, MD, MBA ${ }^{1,2}$ \\ ${ }^{1}$ Department of Ophthalmology, Emory University School of Medicine, Atlanta, Georgia, USA \\ ${ }^{2}$ L.F. Montgomery Ophthalmic Pathology Laboratory, Department of Ophthalmology, Emory \\ University School of Medicine, Atlanta, Georgia, USA
}

\begin{abstract}
Chondroid syringoma is a benign mixed tumor characterized by sweat gland elements in a cartilaginous stroma. This rare tumor accounts for only $0.01 \%$ of all primary skin tumors and occurs only rarely in the periorbital region. Chondroid syringomas are usually 0.5 to $3.0 \mathrm{~cm}$ in size, with increased risk of malignancy in tumors larger than $3.0 \mathrm{~cm}$. Here we report a rare case of giant chondroid syringoma arising in the lower eyelid, characterized by an epithelial component in a cartilaginous stroma.
\end{abstract}

\section{Precis}

We present a case of giant chondroid syringoma characterized by a mixed tumor with a prominent cartilaginous component

Chondroid syringoma is a rare mixed tumor accounting for only $0.01 \%$ of all primary skin tumors. ${ }^{1}$ These tumors most commonly occur in the head and neck region but only a minority arise in periorbital tissues. ${ }^{2}$ These are usually slow-growing, asymptomatic, solitary, nonulcerating masses ranging between 0.5 to $3.0 \mathrm{~cm}$ in size. ${ }^{3}$ Here we report a rare case of giant chondroid syringoma arising in the lower eyelid. This case information was collected and evaluated in a manner compliant with the Health Insurance Portability and Accountability Act (HIPAA).

\section{Case Report}

A 41-year-old white male presented with a slow-growing mass on the right lower eyelid (Fig 1). The lesion had been present for the previous four years, with more rapid growth in the year prior to exam leading to a mechanical ectropion. On physical exam, the mass was nontender, multilobulated, firm, and freely movable within the dermis. No other rashes or lesions were noted along the eyelid. Visual acuity, extraocular movements, confrontation visual fields, and other findings on visual exam were all normal. The patient reported

Corresponding author: Hans E. Grossniklaus MD, BT 428 Emory Eye Center, 1365 Clifton Road, Atlanta, GA, 30322, FAX: 404-778-4610, ophtheg@emory.edu.

The authors have no financial interest in anything in this manuscript. 
occasional pain and throbbing in the lesion and periods of bleeding in the nasal area at night, including the month prior to presentation.

Biopsy revealed areas of cartilage and cords of cells with pleomorphic round-to-oval nuclei and abundant eosinophilic cytoplasm. Scattered chronic inflammatory cells were also present within fibrovascular tissue next to cartilage. The histopathological diagnosis was of chondroid syringoma. The tumor was excised en bloc under general anesthesia and the site repaired with a laterally-based skin-muscle flap and a tarsal strip to tighten the lid margin.

The resected tumor was a smooth multilobulated mass covered with an ellipse of skin measuring $52 \times 38.5 \times 33 \mathrm{~mm}$ (Fig 2). Histopathological analysis revealed an encapsulated tumor within the dermis containing both epithelial and mesenchymal components (Fig 3). The epithelium was composed of tubules lined by low cuboidal epithelial cells surrounded by myoepithelial cells. Myoepithelial cells blended into the surrounding stroma, in some areas forming sheets. The surrounding stroma contained large amounts of cartilage and some bone fragments. Toluidine blue stain and electron microscopy images showed cells with large, round, displaced nuclei and prominent nucleoli. The cells displayed abundant cytoplasm and no intercellular junctions but did have some intracytoplasmic mitochondria and occasional intermediate filaments. The extracellular matrix showed somewhat electron dense material. No atypical cells or mitoses were noted, and resection margins indicated the tumor had been completely excised. Diagnosis of chondroid syringoma, a benign mixed tumor, was confirmed.

\section{Discussion}

Chondroid syringoma is a rare mixed tumor of sweat gland origin first described in 1859 by Bilroth as a tumor type similar to benign mixed tumor of salivary glands. Hirsch and Helwig later classified this tumor type as chondroid syringoma in $1961^{1}$ due to the presence of sweat gland elements in a cartilaginous stroma. Incidence of chondroid syringoma is between 0.01 and $0.1 \%$ of all skin lesions.

Tumors usually range in size from 0.5 to $3.0 \mathrm{~cm}$ and are typically painless, slow-growing masses present for multiple years prior to presentation. ${ }^{3}$ Chondroid syringomas most commonly occur in the head and neck regions. Only 26 cases of chondroid syringoma in the periorbital region were reported through $2006,{ }^{2}$ and few additional cases have been reported in the four years prior to this case. There is only one other recent report of giant chondroid syringoma $(>3.0 \mathrm{~cm})$ of the eyelid. ${ }^{4}$

The differential diagnosis of chondroid syringoma may include neurofibroma, dermoid cysts, sebaceous cysts, dermatofibroma, salivary gland pleomorphic adenoma, or basal cell carcinoma. ${ }^{5}$ Diagnosis is confirmed with biopsy of the mass demonstrating nests of cells and ducts surrounded by chondromyxoid stroma. ${ }^{6}$ The tumor may arise from eccrine or apocrine sweat glands, with some tumors showing features of both types. ${ }^{2}$ The apocrine tumor type is more common and characterized by branching lumina lined by two layers of epithelial cells. The eccrine type, in contrast, has smaller lumina lined by a single epithelial layer. The 
mesenchymal stroma may be chondroid, as in the present case, or myxoid, adipocytic, or fibrous. Rarely, osteoid stroma and mature adipocytes may be observed. ${ }^{1}$

The risk of malignancy increases with giant chondroid syringomas greater than $3.0 \mathrm{~cm}$ in size, although malignant cases usually arise de novo. ${ }^{3}$ Only 30 malignant cases of chondroid syringoma were described as of $2013,{ }^{7}$ and these are more likely to occur in women (1.7:1) and in the extremities $\left(60 \%\right.$; $20 \%$ in head and neck). ${ }^{8}$ Atypia, necrosis, abundant mitoses or mucoid matrix, infiltrative margins, and poorly differentiated chondroid components may all suggest malignancy. ${ }^{7} 9$ The treatment in these cases remains excisional biopsy, although such patients should be followed closely due to high risk of recurrence.

In conclusion, chondroid syringoma is a rare benign mixed tumor type that should be included in the differential diagnosis for large eyelid masses. Excisional biopsy remains the treatment of choice, and histopathological assessment should be obtained to confirm the diagnosis and identify any signs of malignancy.

\section{Acknowledgments}

Supported in part by NIH NEI EY06360 and an unrestricted departmental grant from Research to Prevent Blindness, Inc.

\section{References}

1. Hirsch P, Helwig EB. Chondroid syringoma: Mixed tumor of skin, salivary gland type. Arch Dermatol. 1961; 84:835-847. [PubMed: 13907712]

2. Gündüz K, Demirel S, Heper AO, et al. A Rare Case of Atypical Chondroid Syringoma of the Lower Eyelid and Review of the Literature. Survey of Ophthalmology. 2006; 51:280-285. [PubMed: 16644368]

3. Sungur N, Uysal A, Gumus M, et al. An unusual chondroid syringoma. Dermatol Surg. 2003; 29:977-979. [PubMed: 12930345]

4. Kau HC, Tsai CC. Giant chondroid syringoma of the eyelid. Canadian Journal of Ophthalmology. 2013; 48:e63-e64. [PubMed: 23931483]

5. Schulhof Z, Anastassov GE, Lumerman H, et al. Giant benign chondroid syringoma of the cheek: case report and review of the literature. J Oral Maxillofac Surg. 2007; 65:1836-1839. [PubMed: 17719408]

6. Nasit J, Dhruva G. Chondroid syringoma: A diagnosis by fine needle aspiration cytology. Journal of Cutaneous and Aesthetic Surgery. 2012; 5:222. [PubMed: 23112529]

7. Malik R, Saxena A, Kamath N. A rare case of malignant chondroid syringoma of scalp. Indian Dermatol Online J. 2013; 4:236-238. [PubMed: 23984246]

8. Mathiasen RA, Rasgon BM, Rumore G. Malignant Chondroid Syringoma of the Face: A First Reported Case. Otolaryngol Head Neck Surg. 2005; 133:305-307. [PubMed: 16087034]

9. Yavuzer R, Basterzi Y, Sari A, et al. Chondroid syringoma: A diagnosis more frequent than expected. Dermatol Surg. 2003; 29:179-181. [PubMed: 12562350] 


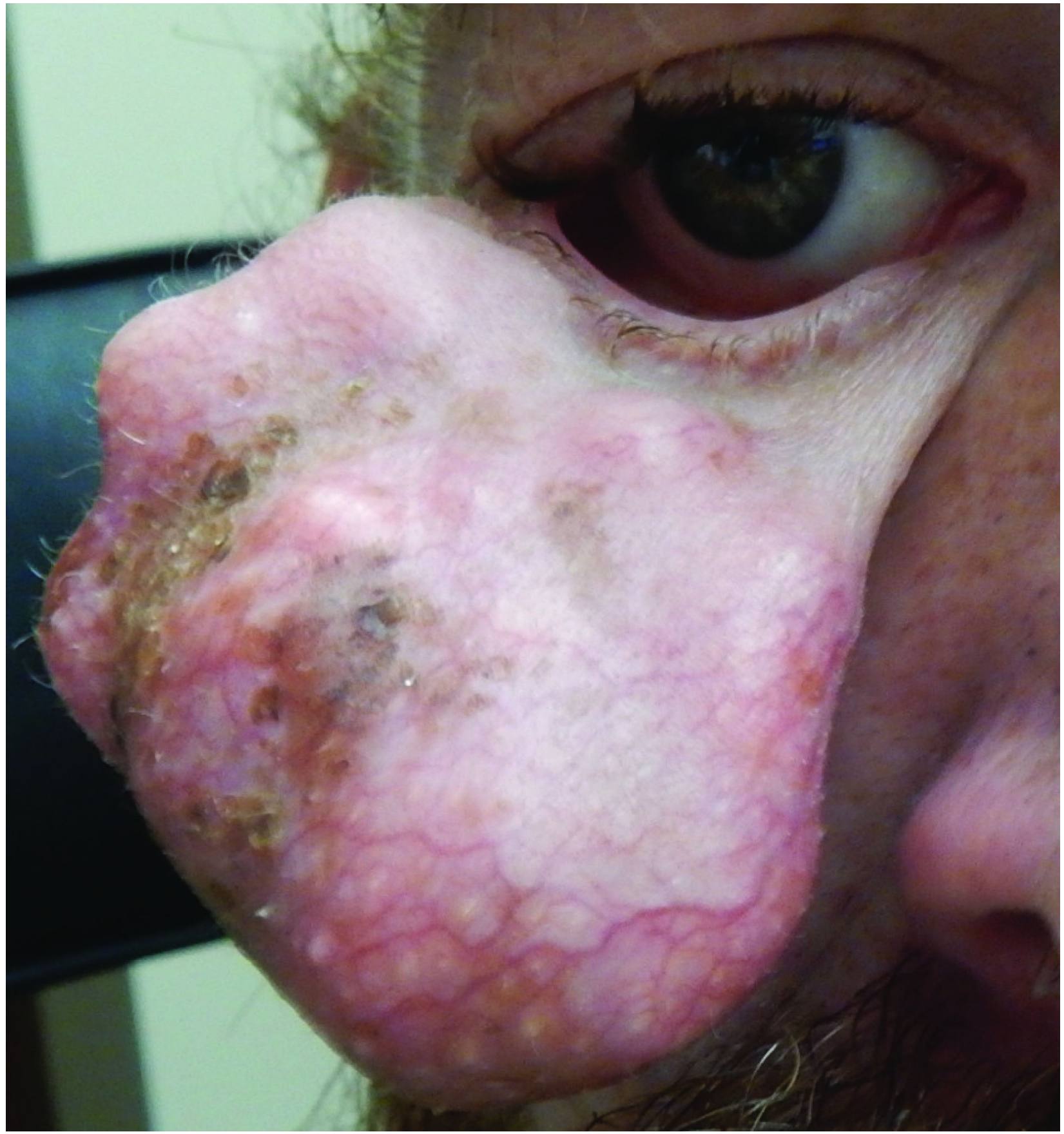

Fig. 1.

Preoperative appearance of tumor on right lower lid exposing the inferior cul-de-sac. 


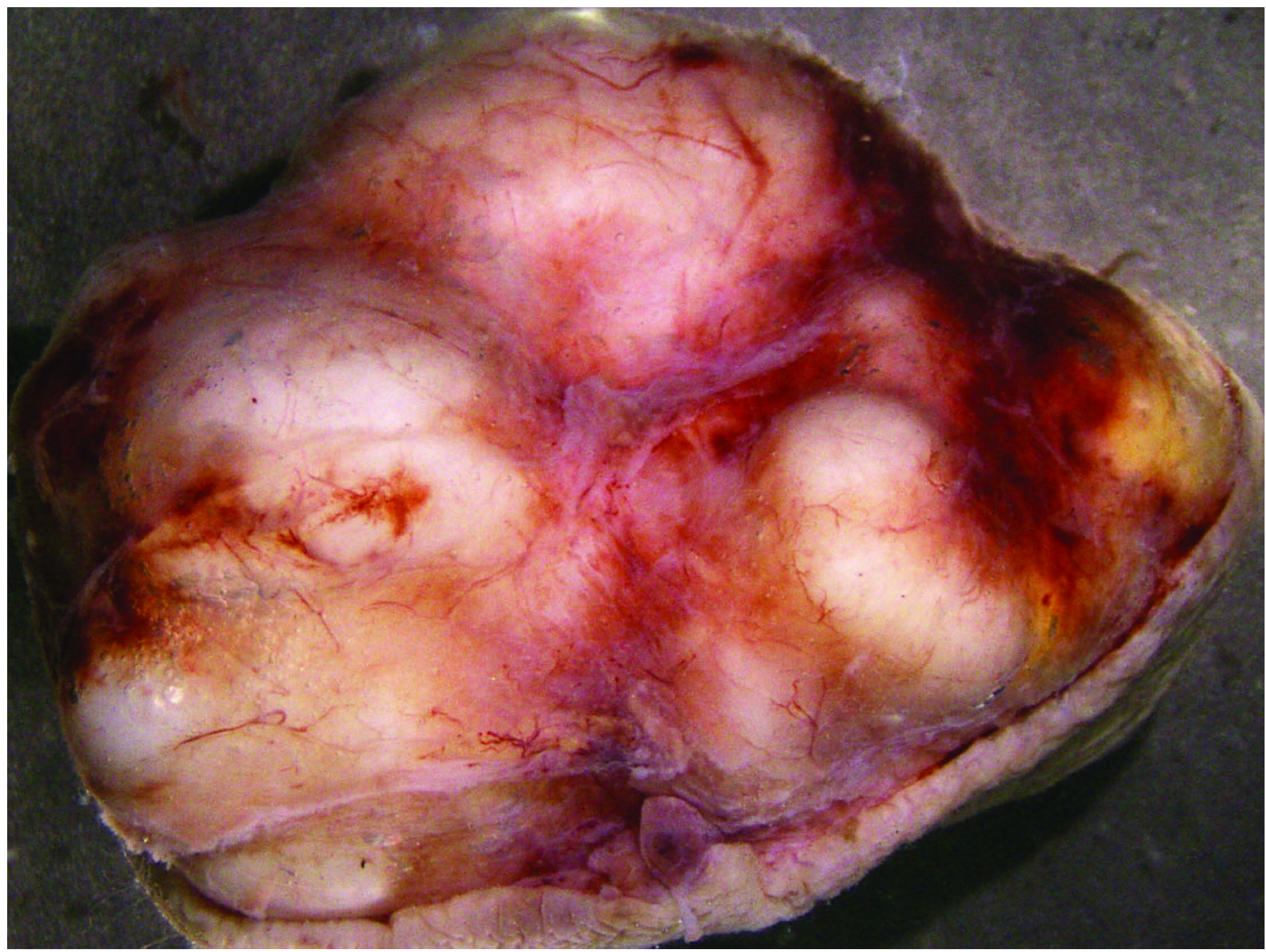

Fig. 2.

Gross resected tumor. The mass was firm, white, multilobulated, and measured $5.2 \times 3.8 \times$ $3.3 \mathrm{~cm}$. 

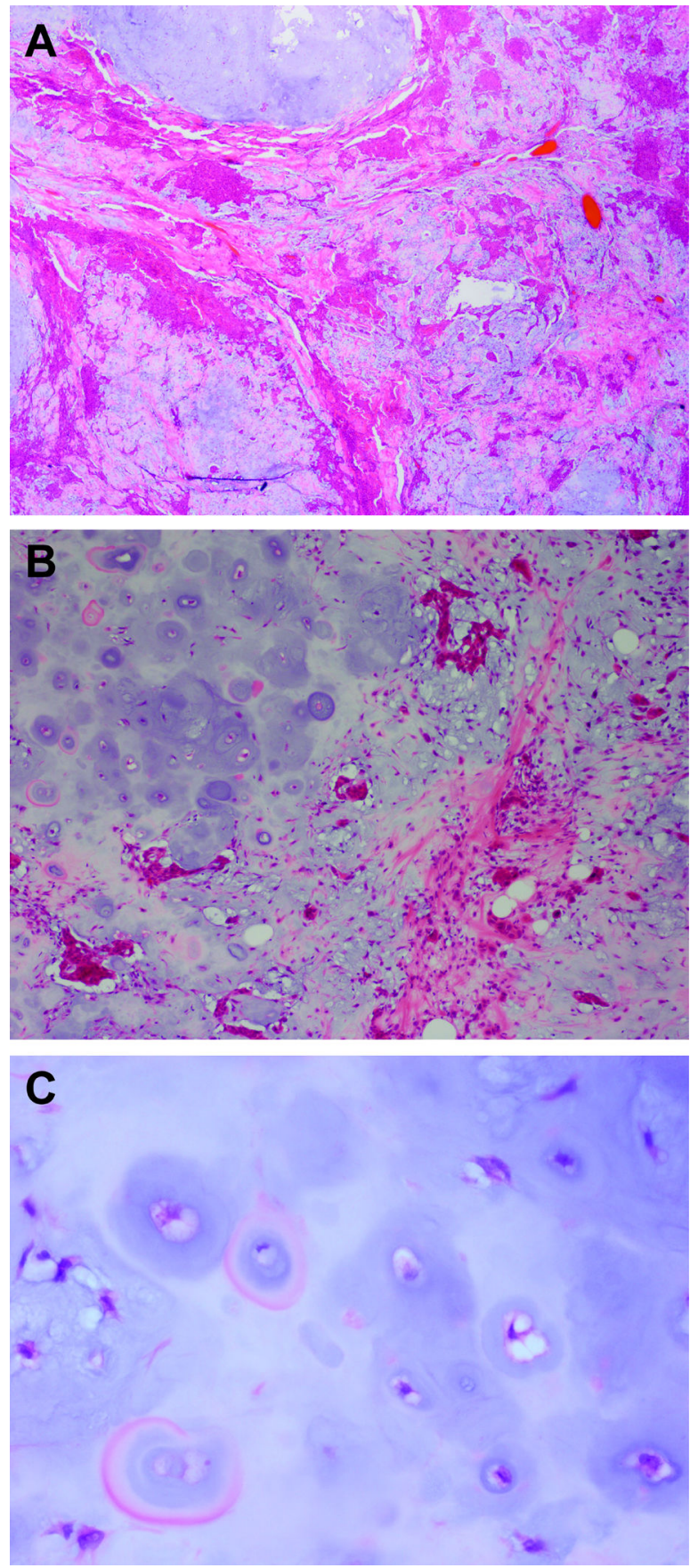

Fig. 3.

(A) The bottom portion of the image shows a mixed tumor with epithelial and stromal components; the top portion shows cartilage. (B) There are islands of ductal epithelium at the interface between mixed tumor at the right and cartilage in the stroma at the left. (C) High magnification of the cartilaginous component of stroma. (A. periodic acid-schiff, 5X; B. hematoxylin and eosin, 25X; C. hematoxylin and eosin, 100X) 